\title{
Research on the Cultivation of Practical Ability of Computer Science and Technology Specialty in Higher Vocational Colleges
}

\author{
Fen Wang, Chong Feng, Bo Sun \\ Shandong Labor Vocational and Technical College, Jinan, Shandong, 250022
}

Keywords: Higher Vocational College, Practical Ability, Computer Science and Technology

\begin{abstract}
Based on the needs of the talent market and the characteristics of the computer science and technology specialty, this paper discusses some reform measures to cultivate students' practice and innovation ability from the aspects of training program, school-enterprise cooperation and engineering practice project construction. Exploration and practice.
\end{abstract}

\section{Introduction}

Since the 1990s, the globalization and informationization of the development of information industry, the extensive application of information technology and the development and utilization of information resources have become the distinguishing feature of the world economic development, and the human society has entered the 21st century One of the important driving forces. The 16th National Congress of the Communist Party of China (CPC) has put forward the strategic thinking of "informationization to promote industrialization, industrialization and informationization" and "taking the road of new industrialization" from the national conditions of our country. With the implementation of this spirit, all levels of government to support the development of electronic information industry unprecedented enthusiasm for the development of the information industry to create a good environment and unlimited business opportunities. "15" period, all levels of information technology talent increased by 20 million people in five years, including software personnel increased by 300 million people, computer personnel need to increase 1 million per year. In our total of 664 undergraduate schools in China, there are 5,050 schools to set up "computer science and technology" professional. In 2004, "computer science and technology" professional school number close to the total number of students in science and engineering $1 / 3$. This reflects the higher education on the national information construction of a positive response, on the other hand also shows that the number of computer professional construction, heavy task.

\section{Computer Science and Technology Professionals Training Status Quo}

National and social needs of the computer professionals, and the national information must be the goal, the process is closely related. The computer market to a large extent determine the level of computer talent, employment, employment and ability to meet the specific requirements. The main reason for the difficulty of employment of computer graduates is not too many or too bad quality, but to meet the needs of social needs is not clear enough, resulting in structural unreasonable. Computer talent training should be matched with the pyramid structure of social needs, it should be the pyramid structure, so as to improve the employment rate of students at all levels of the pyramid, meet the social needs and reduce the cost of re-training.

At present, the understanding of the quality of enterprises and the quality of education in colleges and universities have a greater gap in the connotation. To learn the ability to represent the development potential, is one of the most concerned about the quality of the employer. Enterprises require talent to learn other people's strengths, and now a considerable part of the students "self-centered, blind self-righteousness" weakness is very obvious. 
At present, the proportion of the basic theory courses of computer science is not small. However, because students do not understand their function, many teachers have not imparted the combination of theory and practice to students, so that a large number of students do not attach importance to the basic theory courses. In order to adapt to the rapid development of information technology, more effective training of a large number of computer personnel in line with social needs, all-round to strengthen the construction of computer teachers in colleges and universities without delay.

In view of the above problems, the computer education industry has been carrying out research work, and put forward some effective countermeasures, in which the hierarchical training model is widely recognized. That is, according to the nature of the work of computer graduates engaged in the division of the computer talent is roughly divided into specialized research personnel engaged in research work, engaged in engineering work of specialized personnel, engaged in the application of specialized talents. One of the first to cultivate excellent computer science and technology professionals as the goal, focusing on their future as professors and scholars; the second category focus on training engineering practice talents, focusing on their future as chief engineer, chief engineer; To cultivate professional and skilled, excellent hardware and software production, development, operation, maintenance engineers and professional and technical management engineers as the goal.

In fact, China's educational theory workers have long been from the social function, intelligent structure and other aspects of the study of talent types, that the social talent can be divided into four types: academic talents, engineering talents, technical talents, skilled personnel The The four types of talents, the academic talents require the basic theory of deep, have better academic accomplishment and strong research ability; engineering talent requires a better theoretical basis, strong application of knowledge to solve the practical engineering capacity; Type talent must have a certain theoretical basis, but more emphasis on the application in practice; skills-oriented talent to emphasize job operations. The foundation of theoretical research in local undergraduate colleges is relatively weak, academic talents should not be the main types of training, and technical and technical talents are more suitable for higher vocational colleges and universities. Therefore, the local undergraduate colleges personnel training objectives should be based on engineering personnel training. From the perspective of computer science and technology, engineering is characterized by the evolution of the basic principles of computer science and technology into software or hardware product design, project planning or decision making. Strengthen the practical ability, pay attention to the comprehensive use of professional knowledge, improve the ability to communicate with enterprises is the best means of training such personnel. Vigorously cultivate engineering talents to meet the characteristics of local institutions, but also meet the requirements of individualized teaching.

\section{Practice Innovation Capacity as an Important Goal of Training Programs}

In the design of the curriculum system, the concept is to combine the theoretical basis and practical application, highlight the practice of innovation ability, build a reasonable curriculum system, according to the technical development and talent needs of the situation, constantly adjust the teaching content, reform teaching methods, Personnel training mode of reform in the design of the curriculum system, the main follow the three principles:

(1) The curriculum system should reflect the requirements of training objectives, both to ensure that the basic theory of learning courses, but also take into account the application of the course of learning.

(2) The curriculum system should ensure the integrity of the basic knowledge structure.

(3) The curriculum system should be set up in the course of engineering practice ability to adapt to the needs of technical application talents training. Using "modular approach" to set the course group, which is divided into professional courses and professional courses and professional courses and characteristics of courses group of professional courses in the course of "software technology", "network and information security", "embedded system" three course groups, students can be based 
on the future direction of development and interest to choose one of the course group as the major direction. In order to strengthen the training of students' engineering practice ability, we have set up six engineering practice training programs, especially in the training program.

In the teaching plan arrangement, some important compulsory courses for experimental courses separately, set up "high-level language programming experiment", "data structure and algorithm experiment", "digital logic circuit experiment", "computer composition principle experiment", "oriented object and visual programming experiment "," database technology experiment "," software project development "and other experimental courses. These experimental courses independently set, according to the weekly hours of credits, students must be passed alone through the experimental course assessment. The method of single course makes the students and teachers fully aware of the importance of experimental teaching and promoted the students' practical ability and innovation ability. Under the third semester of the university, through the training platform of school and enterprise cooperation, sent to the two methods, through cooperation with the construction of practical teaching base for students to develop project training in the fourth grade, arrange graduation practice and graduation design links, to further improve students' practical development ability.

\section{Training Mode of Engineering Talents}

With the rapid development of IT technology, Suzhou Industrial Park and Suzhou City I T enterprises have also undergone tremendous changes and the demand for their talent is constantly changing. Therefore, tracking the development of I T enterprises, analysis of their talent needs, the computer professional training model has important reference value. In view of the current situation of many undergraduates cultivating undergraduates difficult to adapt to the market demand, Suzhou University and Suzhou City, the relevant enterprises jointly set up I T Enterprise Teaching Steering Committee for the Suzhou University I T professional development to provide long-term guidance and support. At the same time, I T Enterprise Teaching Steering Committee enterprises from time to time to the computer professional students held technical seminars and cutting-edge knowledge lectures, and teachers to discuss, to discuss the issue of teaching content updates.

Innovative laboratory is an effective way to cultivate students' innovative ability. At present, Suzhou University School of Computer Science and Technology and Motorola China Limited, Suzhou Guoxin Technology Co., Ltd., Zijin Electronics Co., Ltd. and other units jointly established the Suzhou University of Motorola MCU laboratory, Jiangsu Province, embedded software technology center Suzhou University Centers and other scientific research capacity of the laboratory, so as to improve the ability of students to create the conditions for innovation. At the same time, the college set up its own open laboratory, mainly for the computer science and technology college students with excellent academic performance and scientific research ability to provide students with innovative experimental conditions, and developed a comprehensive open laboratory regulation, its operating mechanism and operating mode.

The key to improving practical ability is to give students the opportunity to communicate directly with the business. Therefore, we should actively guide teachers to take the initiative to face the main battlefield of local economic construction, social development and cultural prosperity, and deeply cultivate professional construction in production practice. In practice, change the traditional teaching concept, is committed to cultivate a strong social adaptability of senior specialized personnel. At present, we have established the computer science and technology teaching and practice base in Suzhou Industrial Park, Suzhou New District, Motorola, AMD, Logitech, Wang Hong and other world-renowned IT enterprises, and in cooperation with the Software Engineering Co., Ltd. in Kunshan Suzhou University in a software engineering college practice base. In practice, teaching in practice, making the computer science and technology students' practical ability significantly enhanced.

We divide the business practice into three stages. First, cognitive practice, the time is generally a week, mainly to students a comprehensive understanding of the mode of operation of enterprises, the main research direction and the current popular development tools and hardware and software 
platform. Second, the summer social practice, the time is 50 days, mainly for students to use the summer in-depth enterprises to participate in some small projects or some module development, and even document finishing work, the purpose is to let students know how knowledge can be used in the end how to use and initially with the use of knowledge to carry out some of the practical project development capabilities. Third, graduation practice, the time for a semester, mainly to enable students to use the knowledge to carry out a more complete project development, the purpose is to allow students to graduate with independent competency after the development and design capabilities.

\section{Conclusion}

Strengthen the practice of teaching, students can make the practical ability and innovation ability has been significantly improved. In recent years, our students have repeatedly in Jiangsu Province, programming and web design competition to obtain good results, a graduate employment rate is always more than $98 \%$, talent employment is also very wide. At present, in the construction of the base of practice, we expand the scope of practice base at the same time, pay more attention to the connotation of the practice base construction, such as "multi-mode school-enterprise cooperation to develop high-quality IT talent," the subject of research, hope through IT enterprise teaching guidance Committee, IT enterprise alliance and other loosely coupled school-enterprise cooperation model and build innovative experimental center, practice base and other close school-enterprise cooperation model, etc. to carry out all-round, multi-level cooperation. At the same time, for different levels of students, different nature and size of the enterprise to adopt a flexible and diverse training model, both to cultivate high-quality, innovative talents of the purpose, but also enterprises in the school-enterprise cooperation in the benefits, so as to achieve a win-win school purpose.

\section{References}

[1] Jia Qingjie, He Baofeng.Study on the training mode of computer application talents [J] .Chinese Journal of Adult Education 2009 (11)

[2] Gu Kemin. Research and practice of practical talents training model for computer science [J]. Liaoning Education Research. 2007 (10)

[3] Wang Zhongmin, Wang Luhai, Han Jungang.Study on Practical Teaching Mode of Engineering Applied Talents Cultivation in Engineering Colleges and Universities [J]. Science and Technology Advisory Herald 2007 (30)

[4] Cao Tengyu, Pan Jusu, Fu Qiong.Technology of Innovating School-Enterprise Cooperation with Practice Teaching as the Main Body [J]. China Higher Education. 2007 (10)

[5] Yang Kaofan, Chen Guanlin, Zhu Yong, Liu Jun. "211" training mode of computer application talents [J]. Advocacy of Higher Education. 2006 (01)

[6] Yang Yan, Wei Liangmo, Chen Shuhuai. School-enterprise joint innovation of higher vocational talent training mode, 2007 (03) 